\title{
Direct formation of surface layer's quality parameters during combined treatment of two-phase stainless steel blanks
}

\author{
Eugeny Kiselev ${ }^{1, *}$, and Oleg Blagovskiy ${ }^{2}$ \\ ${ }^{1}$ Ulyanovsk State Technical University, 432027 Ulyanovsk, Russia \\ ${ }^{2}$ Ulyanovsk Mechanical Plant, 432008 Ulyanovsk, Russia
}

\begin{abstract}
The results of experimental studies of formation surface layer's quality parameters (residual stresses and phase composition) forming during combined turning and ultrasonic hardmetal burnishing of blanks made of 07X16H6 two-phase stainless steel are represented. Shows the effect of combined treatment regime on the value and depth of the arising compressive residual stresses and phase composition (volume of austenite). Also demonstrated that the changes in this parameters are distributed to a depth exteeding the allowance for subsequent processing.
\end{abstract}

\section{Introduction}

It is generally known that a significant impact on the performance of the critical parts (in particular, fatigue strength and corrosion resistance) have technological residual stresses (TRS) and phase composition (PC) of the material from which they are made. Using on the final operations of technological process (TP) of manufacturing parts processing methods such as grinding or high speed cutting, coupled with high temperatures in the contact zone of treatment dramatically increases the chance of phase transformations and the formation of the tensile stresses in surface layer, which significantly reduce fatigue and corrosion resistance of the finished product. This problem is particularly acute in the manufacture of parts of the two-phase stainless steels have low thermal conductivity and are prone to phase transformations, in particular, the reverse transition from the $\gamma$-iron to the $\alpha$ iron.

Moreover, the greatest effect on corrosion resistance is the amount of an austenite phase $(\gamma-\mathrm{Fe})$ having a facecentered cubic (FCC) lattice and has an increased chemical resistance and strength at high temperatures [1]. A typical representative of such material is AISI 301 steel (russian analog - 07X16H6), details of which operate in harsh environments and experience cyclic loading. The most widely to ensure a given level of residual stresses and phase composition of the surface layer of thermal methods used (natural or artificial aging, annealing for stress relaxation, partial or complete austenitization to form austenite phase by heating iron alloys to the transformation temperature or above) characterized by high energy and time consuming. Another effective way to accomplish this is to use the methods of surface plastic deformation (diamond or carbide burnishing, etc.).
As known, their limitation is the difficulty in the manufacture of thin-walled and low-rigidly parts. Moreover, using of operations of plastic deformation of the surface in the final stages of TP inevitably leads to the collapse of the austenite in the surface layer of workpieces and reducing the corrosion resistance of the treated surfaces of machine parts. Therefore, to provide the required mechanical properties of the surface layer is necessary to efficiently use the technological heredity (TH) phenomena, creating predetermined residual stresses and phase composition on operation preceding the final one.

Technological heredity is a transfer on the finished product in the manufacturing process errors, mechanical and physico-chemical properties of the initial blank or properties and errors that have emerged in that blank at individual manufacturing operations [2]. With the use of this phenomenon for a given level of technical requirements necessary to establish direct links between quality parameters formed on roughing and finish operations process, or to determine the influence of elements of treatment on the mechanical properties of the surface layer and has preset specifications of manufactured parts.

For example, consider a fragment of manufacturing process of parts made of the two-phase corrosionresistant steel austenitic-martensitic class AISI 301, which includes the operation of combined turning and ultrasonic hardmetal burnishing (UHB) (equipped with a carbide cutter Korloy CCMT 060204-HPF NC8010; burnisher - plate Korloy CNMG 120408-HS NC9025), made on a lathe UT16P (УT16П), and subsequent grinding operation (grinding machine $3 \mathrm{M} 151 \mathrm{~V}$, grinding wheel 1-600x25x305 24AF8M7V35).

Samples in studies served rolls with a diameter of 60 $\mathrm{mm}$ and a length of $200 \mathrm{~mm}$. Ultrasonic vibrations (frequency $f=22 \mathrm{kHz}$, amplitude $A=10-12 \mu \mathrm{m}$ ) was applied to the hardmetal burnisher from ultrasonic

\footnotetext{
Corresponding author: kec.ulstu@mail.ru
} 
generator UZG-641A (У3Г-641A). Burnisher located opposite the turning tool with a lag of $\approx 5 \mathrm{~mm}$.

Turning and grinding processing was carried out applying the tool to the zone of contact with the workpiece $3 \%$ aqueous solution semisynthetic coolant Vels-1 (flow rate: $10 \mathrm{l} / \mathrm{min}$ - turning; $40 \mathrm{l} / \mathrm{min}$ grinding). Surface plastic deformation during combined treatment being fed into the nip with the hardmetal burnisher and blank with $100 \%$ concentrate coolant Vels-1 at a rate of $5 \mathrm{~g}$ per hour by applying it to the objects with a brush.

\section{Results}

As varied factors in determining the elements of the regime combined turning and burnishing provide minimum, maximum and average values of the residual stresses in the surface layer at a depth of grinding allowance $Z_{G}$ considered cutting allowance $t(0.5,0.75$ and $1 \mathrm{~mm})$, the cutting speed $V(47.1,59.3$ and 75.4 $\mathrm{m} / \mathrm{min})$, feed $S(0.046,0.054$ and $0.064 \mathrm{~mm} / \mathrm{rev})$ and clamping force $F(100,200$ and $300 \mathrm{~N})$. Some results of experimental studies of residual stresses on the device "Siton-ARM" (“Ситон-APM") showed in Fig. 1 - 4.

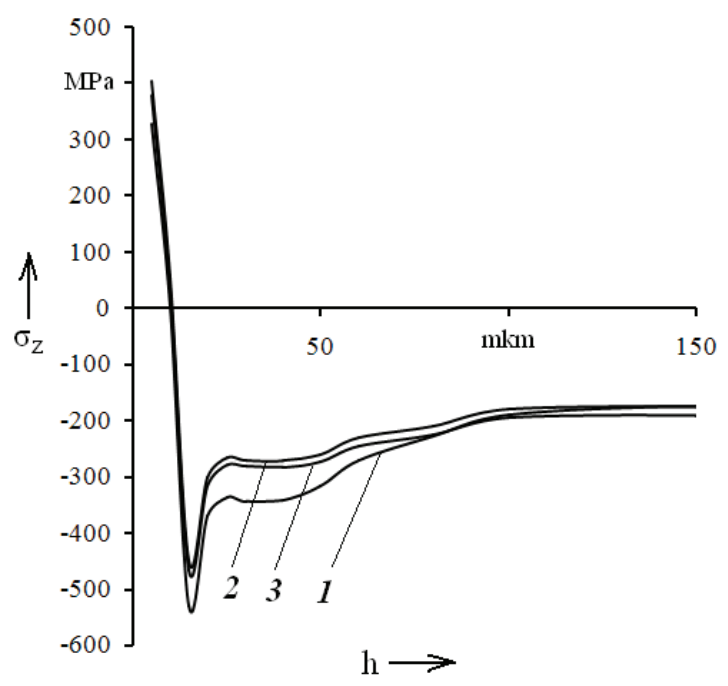

Fig. 1. Diagrams residual stresses after combined treatment by turning and ultrasonic hardmetal burnishing with various allowance: $1-\mathrm{t}=0,5 \mathrm{~mm} ; 2-\mathrm{t}=0,75 \mathrm{~mm} ; 3-\mathrm{t}=1 \mathrm{~mm}$; other parameters of processing $-\mathrm{V}=59,3 \mathrm{~m} / \mathrm{min} ; \mathrm{S}=0,054$ $\mathrm{mm} / \mathrm{rev} ; \mathrm{P}=200 \mathrm{~N}$.

Shown in Fig. 1 - 4 show the stress distribution ambiguous effect regime change in all elements of the combined treatment on the stress but clamping force $P$. This is due, in our view, with the influence of various processing components of force and contact temperatures in areas of cutting and smoothing, as well as their phase transformations caused by the material of the surface layer.

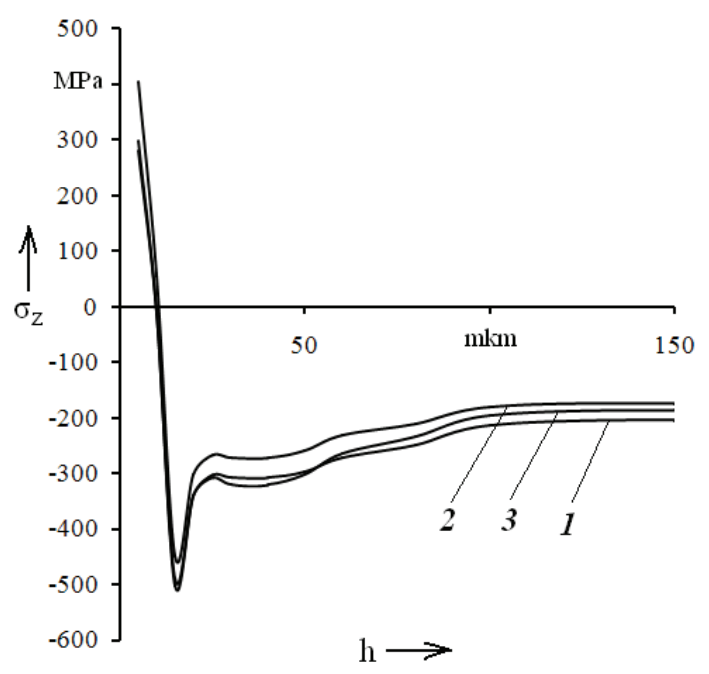

Fig. 2. Diagrams residual stresses after combined treatment by turning and ultrasonic hardmetal burnishing with various cutting speed: $1-\mathrm{V}=47,1 \mathrm{~m} / \mathrm{min} ; 2-\mathrm{V}=59,3 \mathrm{~m} / \mathrm{min} ; 3-\mathrm{V}$ $=75,4 \mathrm{~m} / \mathrm{min}$; other parameters of processing $-\mathrm{t}=0,75 \mathrm{~mm} ; \mathrm{S}$ $=0,054 \mathrm{~mm} / \mathrm{rev} ; \mathrm{P}=200 \mathrm{~N}$.

After analyzing the data, were selected three sets of elements for the combined treatment, providing maximum, medium and minimum residual stresses at a depth of subsequent grinding allowance $(0.1 \mathrm{~mm})$. Processed on these modes combined workpiece acted on the subsequent grinding. The diagrams illustrate the effect of technological heredity of residual stresses. If, after the combined treatment for a subsequent grinding depth were formed on the maximum value of the compressive residual stress, after removal of allowance on subsequent processing step, in forming the surface layer preform minimum tensile stress. The same dependence is observed for the remaining two pairs of diagrams.

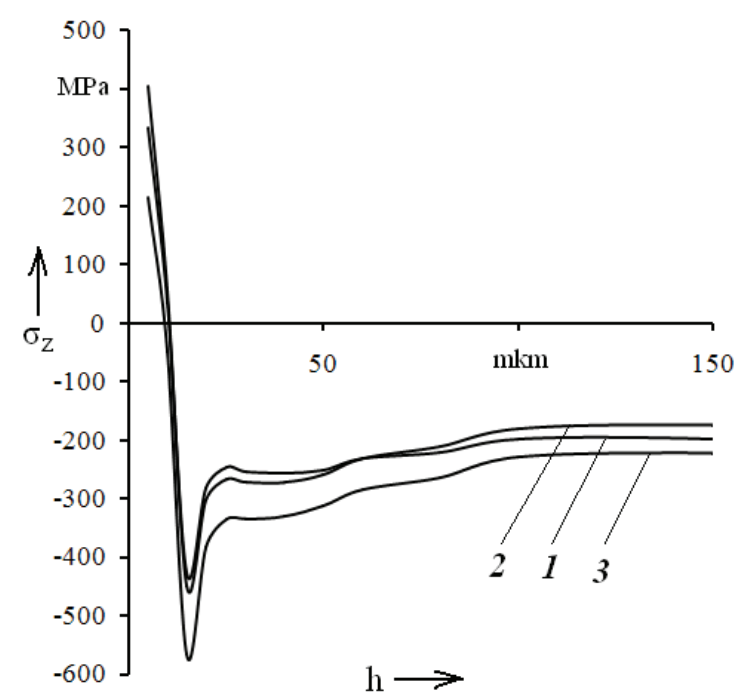

Fig. 3. Diagrams residual stresses after combined treatment by turning and ultrasonic hardmetal burnishing with various feed: $1-S=0,046 \mathrm{~mm} / \mathrm{rev} ; 2-S=0,054 \mathrm{~mm} / \mathrm{rev} ; 3-S=0,064$ $\mathrm{mm} / \mathrm{rev}$; other parameters of processing $-t=0,75 \mathrm{~mm} ; V_{3}=$ $59,3 \mathrm{~m} / \mathrm{min} ; P=200 \mathrm{~N}$. 


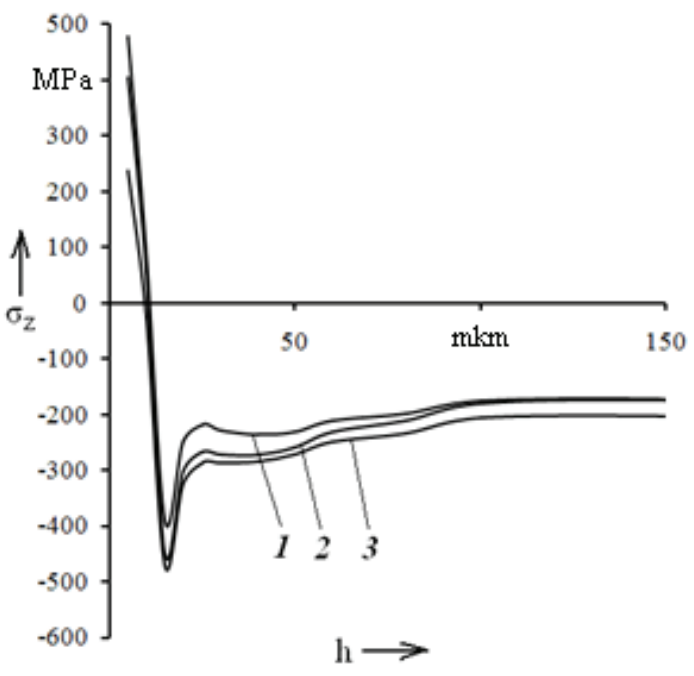

Fig. 4. Diagrams residual stresses after combined treatment by turning and ultrasonic hardmetal burnishing with various clamping force: $1-P=100 \mathrm{~N} ; 2-P=200 \mathrm{~N} ; 3-P=300 \mathrm{~N}$; other parameters of processing $-t=0,75 \mathrm{~mm} ; V_{3}=59,3$ $\mathrm{m} / \mathrm{min} ; S=0,054 \mathrm{~mm} / \mathrm{rev}$.

Experimental studies of technological inheritance of phase composition of the surface layer of the two-phase austenitic-martensitic corrosion-resistant steel AISI 301 produced by the X-ray measuring complex "RIKOR-7" ("РИКОР-7"), during which the intensity of the peaks monitored $\alpha$-iron (martensite) and $\gamma$-iron (austenite) in grinded samples, which is then translated into the percentage by volume of austenite in surface layer. The results are shown in Fig. 5 - 6.
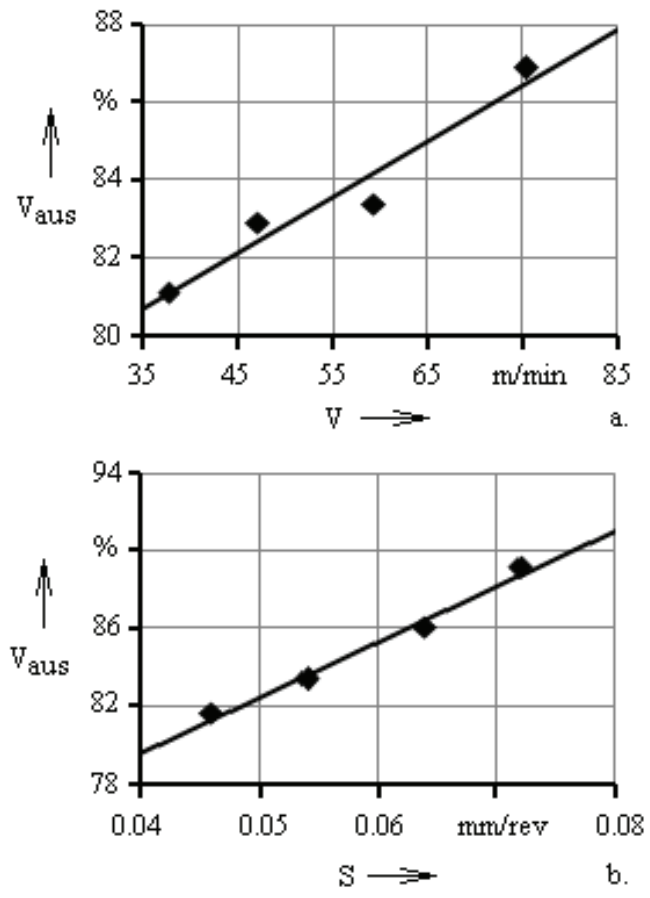

Fig. 5. Dependence of the amount of the austenite phase in the surface layer blanks made of corrosion-resistant steel AISI 301 of different regime elements of combined treatment turning and ultrasonic hardmetal burnishing.

Blanks were pretreated combined turning and burnishing with different regime elements (see Fig. 5), and then polished with infeed (see Fig. 6). Thus, the influence of determined elements for the pretreatment (allowance $t$, cutting speed $V$, feed $S$ and clamping force $P$ ) on the percentage of austenite in grinded samples.
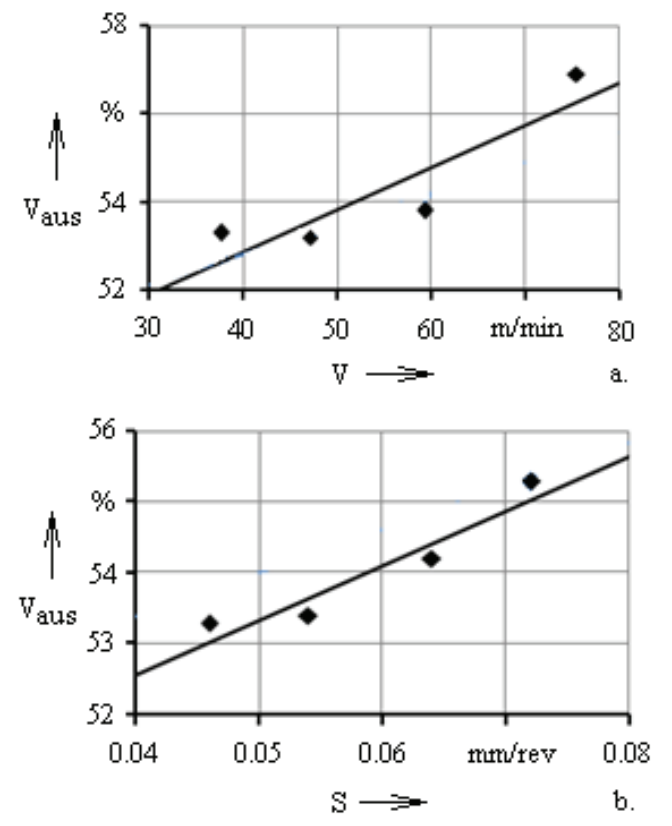

Fig. 6. Dependence of the amount of the austenite phase in the surface layer grinded blanks made of corrosion-resistant steel AISI 301 after combined treatment with the different regime elements.

After analyzing the experimental results, it can be argued that the cutting speed $V$ and feed $S$ have little effect on the amount inherited austenite (since changing his percentage is less than $5 \%$ of the surface layer). Growth of the allowance $t$, according experimental results, reduces the amount of austenite in grinded workpieces by almost $10 \%$.

A similar pattern is observed with increasing of clamping force $P$, where the decline in the amount of austenite is $17 \%$.

\section{Summary}

The results obtained are, in our opinion, as in the case of changing the residual stresses associated with the radial force components of the combined treatment, causing the austenite, and also the influence on the formation and decomposition of austenite grains in a superficial layer formed on the workpiece stage pretreatment residual stresses.

The results of the research, the following conclusions:

1. Using of combination treatment in the preliminary stages of the technological process allows to generate a sufficiently large in magnitude residual stresses at a depth greater than the amount of allowance for subsequent grinding. Taking into account that because of the large thermal stress in the process of grinding the surface layer formed blanks tensile residual stresses, the total value of stresses will be determined by their sum. 
2. Significant impact force, which involves surgery combined treatment may have a negative effect on the phase composition of the surface layer of parts made of corrosion-resistant steel, causing it to decay of austenite. As the results of experimental studies, such as phase transformations extend deeper than allowance for subsequent treatment and due technological heredity phenomena, are transferred to the finished part.

3. Changing elements of the regime combined treatment can effectively provide a predetermined amount of residual stresses and phase composition of the surface layer of the items in accordance with the specifications of the finished product. However, the question of formation of residual stresses and phase composition during the preliminary combined treatment should be addressed comprehensively, as the choice of treatment regimen, providing a predetermined compressive stresses can lead to a substantial decrease in the austenite phase and, consequently, to reduce the corrosion resistance of surfaces of parts.

\section{References}

1. Y. Solntsev, Metals and alloys. Handbook (2003)

2. A. Dalski, Technological ensuring of precision parts reliability (1975) 